\title{
COMMUNICATION
}

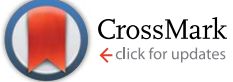

Cite this: RSC Adv., 2016, 6, 57306

Received 16th May 2016 Accepted 7th June 2016

DOI: $10.1039 / c 6 r a 12731 b$

www.rsc.org/advances

\section{Rational design of a supramolecular gel based on a Zn(II)-salophen bis-dipeptide derivative $\uparrow$}

\author{
Martina Piccinno, ${ }^{\text {ab }}$ César A. Angulo-Pachón, ${ }^{c}$ Pablo Ballester, ${ }^{\text {bd }}$ Beatriu Escuder ${ }^{\star c}$ \\ and Antonella Dalla Cort ${ }^{\star a}$
}

The field of low-molecular-weight gelators (LMWGs) that selfassemble through specific non-covalent interactions has increased enormously in the last decade. ${ }^{1-6}$ At its early stages, gels were found by serendipity. Nowadays, thanks to the progress in the supramolecular self-assembly processes, there is a deeper understanding of the structural features that control the gelation event allowing the rational design of new molecular gelators. ${ }^{1,7,8}$ As a step forward, driven by the increasing number of applications of these soft materials, ${ }^{9-13}$ research efforts have been devoted to the modification of the molecular structure of the gelator to introduce specific functionalities able to promote responses to physical or chemical external stimuli. ${ }^{\mathbf{1 4 - 2 0}}$

Zn(II)-salophen complexes are a popular class of compounds used in supramolecular chemistry. Salophen ligands are easily obtained through the condensation of $o$-phenylendiamine with two equivalents of salicylaldehyde. They strongly coordinate to one zinc(II) metal centre forming thermodynamically stable

${ }^{a}$ Dipartimento di Chimica and IMC-CNR, Universitá "La Sapienza", Piazzale Aldo Moro, 5, 00185 Rome, Italy.E-mail: antonella.dallacort@uniroma1.it

${ }^{b}$ Institute of Chemical Research of Catalonia (ICIQ), The Barcelona Institute of Science and Technology, Avda. Països Catalans 16, 43007 Tarragona, Spain. E-mail: pballester@iciq.es

'Departament de Quimica Inorgànica i Orgànica, Universitat Jaume I, 12071 Castelló, Spain.E-mail: escuder@uji.es

${ }^{d}$ Catalan Institution of Research and Advanced Studies (ICREA), Passeig Lluis Companys 23, 08010 Barcelona, Spain

$\dagger$ Electronic supplementary information (ESI) available: Experimental details, NMR, mass, UV-Vis spectra and DLS analysis. See DOI: 10.1039/c6ra12731b complexes. The possibility of functionalizing any of the starting building blocks, i.e. the amine and the salicylaldehyde provides easy access to a wide variety of metal-salophen derivatives in which the role of the metal coordination geometry is fundamental for the properties of the complex. In the case of zinc(II), the metal centre typically features a distorted square pyramid coordination geometry, the square-planar base is defined by the four $\mathrm{N}_{2} \mathrm{O}_{2}$-donor atoms, while the axial position is generally occupied by solvent molecules or other guests, neutral or anionic, having electron-rich atoms.

Indeed, the ability of $\mathrm{Zn}$ (II)-salophens to form thermodynamically highly stable complexes with amines and anions is well documented in the literature. ${ }^{21-26}$ In the absence of external guests or electron-donating solvents, the Lewis acidic zinc metal centre saturates its penta-coordinated sphere upon binding with the phenolic oxygen atom of another salophen molecule forming thermodynamically highly stable dimers and oligomers that further self-assemble into nanofibers. ${ }^{27-29}$

Herein we report the design, synthesis and gelation studies of an unprecedented supramolecular gelator, 1, based on a $\mathrm{Zn}$ (II)salophen derivative, symmetrically functionalized with two divergent residues comprising L-valine dimers. We also describe the behaviour of the supramolecular gel derived from the selfassembly of 1 in the presence of anionic guests and amines (Fig. 1).

The convergent synthesis of $\mathbf{1}$ involved the initial copper catalysed cycloaddition reaction (click reaction) between

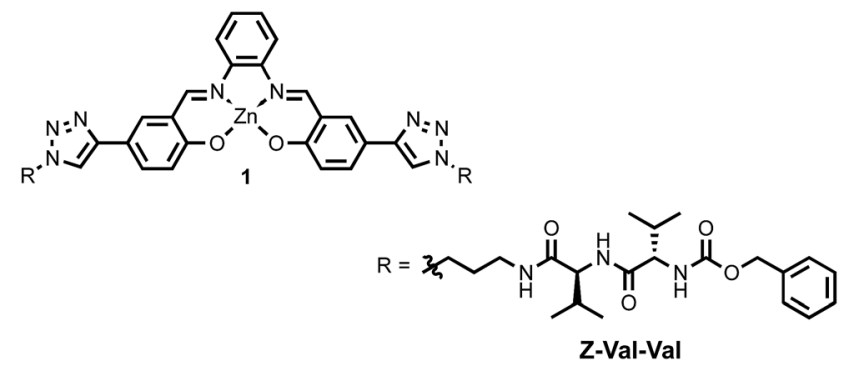

Fig. 1 Line drawing structure of gelator 1. 
5-ethynyl-2-hydroxybenzaldehyde and the azide derivative of the Z-Val-Val residue (Fig. 1). Zn(II)-salophen 1 was obtained uneventfully using standard reaction conditions and the previously prepared Val-fuctionalized-2-hydroxybenzaldehyde II (see $\mathrm{ESI} \dagger$ for details).

Compound 1 was fully characterized using 1- and 2-D NMR techniques, as well as high-resolution mass spectrometry. With respect to solubility, $\mathbf{1}$ did not dissolve in non-polar organic solvents but it was soluble in DMSO and DMF.

Therefore, in order to study the gelation ability of $\mathbf{1}$, we prepared a concentrated stock solution in DMSO $([\mathbf{1}]=20 \mathrm{mg}$ $\mathrm{mL}^{-1}$ ) and used it as source of the putative gelator. We tested the gelation properties of $\mathbf{1}$ using a wide variety of organic solvents. Remarkably, only acetonitrile was gelled when added to a solution of 1 in DMSO. Indeed, the addition of $250 \mu \mathrm{l}$ of acetonitrile to $50 \mu \mathrm{l}$ of the stock DMSO solution containing 1 caused instantaneous gelation of the solvent without the need of sonication or heating.

The aggregation of $\mathbf{1}$ was evidenced both in solution and in the gas phase. The analysis of the gel using MALDI-MS showed the presence of an ion peak at the $\mathrm{m} / \mathrm{z}$ ratio corresponding to $[\mathbf{1} \cdot \mathrm{H}]^{+}$. The isotopic pattern observed for the ion peak was in complete agreement with the theoretical one. In addition, ion peaks corresponding to aggregates of 1 containing up to five monomers were also observed in the MS spectrum (Fig. S8 and S9, ESI $\dagger$ ). Dynamic light scattering (DLS) measurements indicated the presence of particles with sizes in the range of 180-200 $\mathrm{nm}$ (Fig. S10, ESI $\dagger$ ). Notably, when the experiment was repeated using an acetonitrile containing $20 \%$ of DMSO, the DLS analysis indicated the disappearance of the above mentioned size bands supporting the complete disruption of the aggregates of $\mathbf{1}$.

The ${ }^{1} \mathrm{H}$-NMR spectrum of the gel $\left(4 \mathrm{mg} \mathrm{mL}{ }^{-1}\right)$ in $\mathrm{ACN}-d_{3} /$ DMSO- $d_{6} 5: 1$, showed broad signals for the protons of 1 suggesting a certain degree of aggregation for the compound under these conditions. We performed variable temperature ${ }^{1} \mathrm{H}-\mathrm{NMR}$ experiments in the range of $298-353 \mathrm{~K}$ using the above

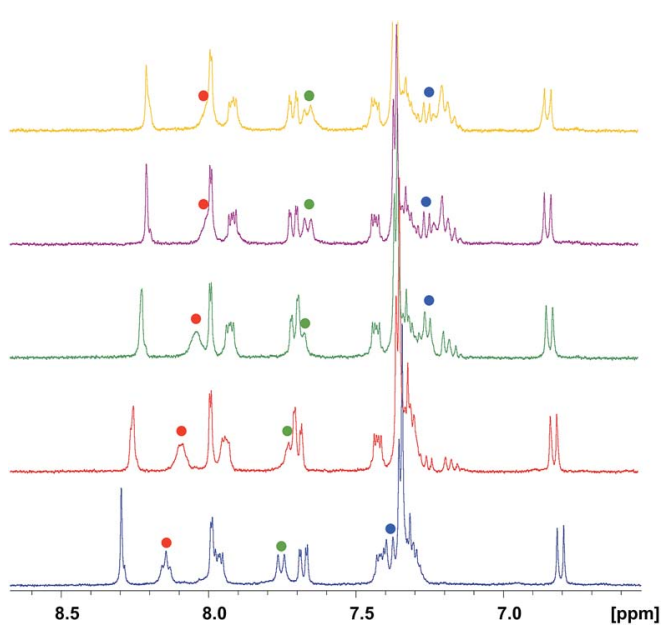

Fig. 2 Selected region of the ${ }^{1} \mathrm{H}-\mathrm{NMR}$ of 1 in DMSO- $d_{6}$, upon addition of $0,100,200,300,400 \mu$ lof ACN- $d_{3}$ (bottom to top). Red, green and blue dots highlight the three amidic hydrogens of the Z-Val-Val fragment. solution (Fig. S7, ESI $\dagger$ ). The increase in temperature caused the sharpening of the broad signals. At $353 \mathrm{~K}$, the ${ }^{1} \mathrm{H}-\mathrm{NMR}$ spectrum showed well defined and sharp proton signals that were almost identical to those observed in the spectrum for $\mathrm{Zn}$ (II)salophen 1 in DMSO solution, where the compound exists in solution as a monomer. These results clearly indicate that the aggregation process of $\mathbf{1}$ was solvent and temperature dependent.

Further insight into the solvent dependent aggregation process was provided by adding incremental amounts of acetonitrile to a $4 \mathrm{mM}$ DMSO- $d_{6}$ solution of 1 . The process was monitored by ${ }^{1} \mathrm{H}$-NMR spectroscopy (Fig. 2). The addition of incremental quantities of ACN- $d_{3}$ caused broadening of the proton signals. This was especially evident in the aromatic region of the spectra. Moreover, the amide $\mathrm{NH}$ protons shifted downfield (0.1-0.2 ppm) as previously reported for $\mathrm{L}$-valine gelators. ${ }^{7}$ Taken together, these observations suggested that the acetonitrile-dependent aggregation process of $\mathbf{1}$ was driven by the formation of hydrogen bond interactions between the L-valine residues.

In order to gain some insight into the morphological properties of the gel, we carried out a transmission electron microscopy (TEM) analysis (Fig. 3). The TEM images revealed the existence of bundles of twisted fibers that grew from nucleation points. The bundles dimensions are in agreement with the particle size determined by the DLS analysis. A closer look to the obtained images allowed us to determine that the twisted fibers forming the bundles were approximately $20 \mathrm{~nm}$ in width. Although it was difficult to assign unambiguously the sense of the twist, the observation of fibres with helicoidal structure supported a transfer of the point chirality present in the molecular component $\mathbf{1}$ to that of the assembled supramolecular material. On the other hand, the good contrast seen for the assembled objects without the need of any additional staining or shadowing suggested a homogeneous distribution of the zinc atoms in the helical fibers.

As mentioned previously, $\mathrm{Zn}(\mathrm{II})$-salophens are good receptors for amines and anions. ${ }^{30}$ Hence, we also tested the gelation behaviour of 1 in the presence of well-known $\mathrm{Zn}$ (II)-salophen guests (Table 1). When one equivalent of the halide, as
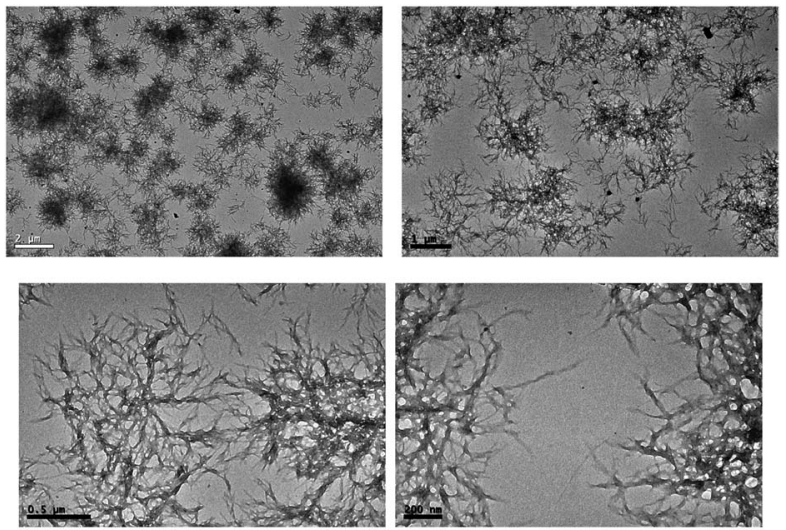

Fig. 3 TEM images of the xerogel of 1. 
tetrabutylammonium salt, was present in solution, the gel was still obtained. However, we observed that the decrease in concentration of gelator $\mathbf{1}$ produced weaker gels. In fact for concentrations of 1 below $3 \mathrm{mg} \mathrm{mL} \mathrm{mL}^{-1}$ the gel survived only in the presence of one equivalent of iodide. Under similar conditions, with added one equivalent of chloride and bromide the obtained gel was unstable to the tube inversion test. Remarkably, the use of fluoride completely prevented the gel formation. These results can be rationalized in terms of anion basicity. Amide NHs are good hydrogen-bond donors and are widely exploited as binding sites for anion recognition (ion-dipole interaction). Fluoride, the most basic halide in the series, is the most effective in preventing gel formation by interfering with the hydrogen bond network that stabilizes it. The interaction of fluoride with amide NHs may even led to deprotonation. ${ }^{31}$

The gel was also formed in the presence of dihydrogen phosphate and benzoate anions. In contrast, in the presence of acetate the formed aggregates did not resist to the tube inversion test. These results further indicate the crucial role played by anion's basicity. The incorporation of amines (one equivalent) rendered very different results for the gel formation. Ditopic diamines like 1,4-diazabicyclo[2.2.2]octane (DABCO) and 4,4'-bipyridine did not inhibit the gel formation. Even a monotopic and very basic amine like quinuclidine was ineffective in preventing gel formation. Surprisingly, the presence of pyridine in solution prevented the gelation properties of $\mathbf{1}$. Clearly the obtained results cannot be rationalized in terms of basicity, quinuclidine is the most basic amine in the series and did not inhibit gel formation. We hypothesize that pyridine, owing to its planar structure that allows its effective intercalation between the aromatic surfaces of the salophen units, can prevent gel formation. In turn, this process will decrease the extent of the $\pi-\pi$ stacking interactions, weakening the thermodynamic stability of the gel. ${ }^{32}$

All together, the obtained results for the experiments of gel formation in the presence of added guest shed some light on the main intermolecular interactions involved in its formation. The intermolecular hydrogen bonds established between the L-valine residues of monomers 1 located one on top of another must play a fundamental role in gel formation. The

Table 1 Gelation ability of 1 ( $c=3 \mathrm{mg} \mathrm{mL}^{-1}$ in $\mathrm{CH}_{3} \mathrm{CN} / \mathrm{DMSO} 5: 1$ ) in the presence of one equivalent of external guests

\begin{tabular}{lc}
\hline Guest & Gel \\
\hline $\mathrm{F}^{-}$ & $\mathrm{Yes}^{a}$ \\
$\mathrm{Cl}^{-}$ & $\mathrm{Yes}^{a}$ \\
$\mathrm{Br}^{-}$ & $\mathrm{Yes}^{a}$ \\
$\mathrm{I}^{-}$ & Yes \\
$\mathrm{AcO}^{-}$ & $\mathrm{No}$ \\
$\mathrm{H}_{2} \mathrm{PO}_{4}{ }^{-}$ & Yes \\
Benzoate $_{\text {Quinuclidine }}$ & Yes \\
DABCO & Yes \\
Pyridine & Yes \\
$4,4^{\prime}$-bipyridine & No \\
${ }^{a}$ Decreasing the concentration of 1 the gel did not form. & Yes
\end{tabular}

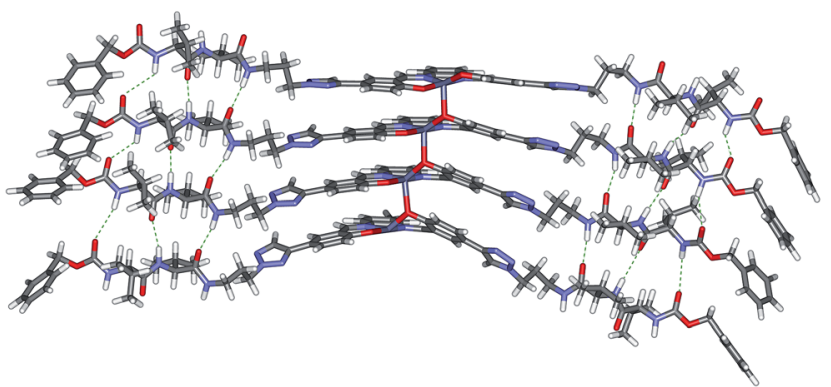

Fig. 4 Energy minimized structure (MM3) of the tetramer of $1 .^{35}$

intermolecular $\pi-\pi$ stacking interactions present in the columnar arrangement of monomers of 1 must also be taken into consideration. In addition, previous reports have demonstrated the ability of $\mathrm{Zn}$ (II)-salophens to aggregate into gels and nanofibers through $\mathrm{Zn} \cdots \mathrm{O}$ interactions occurring between adjacent Zn(II)-salophen units in a columnar stack. ${ }^{28,29,33,34}$ Also in the case at hand, simple molecular modelling studies suggested the possible existence of such interactions (Fig. 4).

We assume that the latter $\mathrm{Zn} \cdots \mathrm{O}$ interactions play a minor role in the thermodynamic stabilization of the gel. In this sense, we have shown above that the presence of certain external amines able to axially coordinate to the zinc metal center (e.g. quinuclidine) did not prevent gel formation.

The absorption spectrum of the gel derived from $\mathrm{Zn}$ (II)-salophen 1 was registered in the range 250-600 nm (Fig. 5). It closely resembled the absorption profile of $\mathrm{Zn}$ (II)-salophen derivatives, with a broad absorption band centred at $420 \mathrm{~nm} .^{21}$ The extinction coefficient value $(\varepsilon)$ of $\mathbf{1}$ in the gel was one order of magnitude smaller than that of $\mathrm{Zn}$ (II)-salophen derivatives in solution. Remarkably, the presence of one equivalent of DABCO caused an increase of absorbance along with a red shift in the 400-450 nm region (Fig. 5, blue line). The red shift of the band is the expected behaviour for the axial coordination of tertiary amines to $\mathrm{Zn}$ (II)-salophens. ${ }^{21}$

This observation indicated that the chemosensing properties of $\mathrm{Zn}$ (II)-salophens are not restricted to solution, but can be also exploited in the gel phase.

In conclusion we report the preparation of an unprecedented $\mathrm{Zn}$ (II)-salophen, 1, functionalized with bis-L-valine residues.

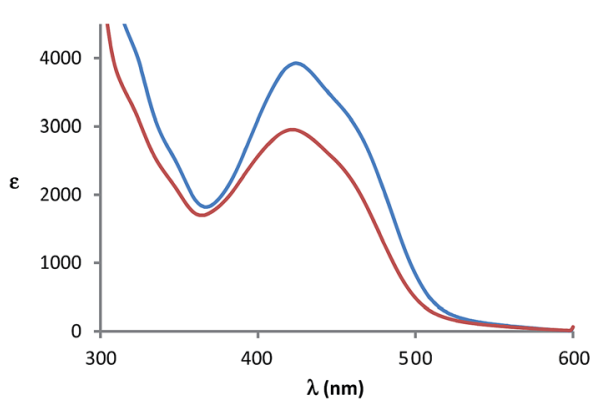

Fig. 5 UV-Vis spectrum of $1\left(3 \mathrm{mg} \mathrm{mL}^{-1}\right.$ in $\left.\mathrm{CH}_{3} \mathrm{CN} / \mathrm{DMSO} 5: 1\right)$ (red) and $1+$ one equivalent of DABCO (blue) in the inset: the gel of $1+$ $\mathrm{DABCO}$ in a $1 \mathrm{~mm}$ pathlength quartz cuvette. 
Compound $\mathbf{1}$ is an effective gelator of acetonitrile solutions. The aggregation process of $\mathbf{1}$ yielding columnar-like fibers is mainly promoted by intermolecular hydrogen bonding between the $\mathrm{NH}$ groups of its bis-L-valine residues. The existence of $\pi-\pi$ stacking interactions between the salophen monomers stacked one on the top of another may also be relevant for the thermodynamic stabilization of the gel. Conversely, the $\mathrm{Zn} \cdots \mathrm{O}$ interactions that can be formed between adjacent monomers of $\mathbf{1}$ in the columnar stack are not very relevant. The presence of anionic guests in solution prevented gel formation. The basicity of the anion can be related to its efficiency in interfering with the hydrogen bonding network established by the L-valine residues. The presence of amines in solution had a reduced effect on gel stability. Only pyridine inhibits gel formation and, according to our hypothesis, this happens because pyridine is the only tested amine able to compete, through insertion between layers, with the $\pi-\pi$ stacking interactions established between the aromatic surfaces of the salophen units.

We also demonstrated that DABCO can bind to the zinc metal center of $\mathbf{1}$ in the gel phase without disrupting it. The axial coordination event can be followed by UV-Vis spectroscopy. This result indicated that gel formation in the case of $\mathbf{1}$ is not significantly promoted by intermolecular $\mathrm{Zn} \cdots \mathrm{O}$ interactions between $\mathrm{Zn}$ (II)-salophen units as was previously reported in related derivatives..$^{\mathbf{2 8 , 2 9 , 3 3 , 3 4}}$ We believe that the described results open new routes for the use of $\mathrm{Zn}$ (II)-salophen units in the construction of guest-responsive gels.

\section{Acknowledgements}

The support and sponsorship provided by COST Actions CM1005 and CM1402 is acknowledged. M. P and A. D. C. acknowledge also "Ricerca scientifica di Ateneo 2014". M. P. and P. B. thank Gobierno de España, Ministerio de Economía y Competitividad (MINECO) (project CTQ2014-56295-R), the Severo Ochoa Excellence Accreditation [2014-2018 (SEV-20130319)], and the Catalan Institute of Chemical Research (ICIQ) Foundation for funding.

\section{Notes and references}

1 J. H. Van Esch and B. L. Feringa, Angew. Chem., Int. Ed., 2000, 39, 2263-2266.

2 D. J. Abdallah and R. G. Weiss, Adv. Mater., 2000, 12, 12371247.

3 J. A. Foster and J. W. Steed, Angew. Chem., Int. Ed., 2010, 49, 6718-6724.

4 X. Yang, G. Zhang and D. Zhang, J. Mater. Chem., 2012, 22, 38.

5 L. Meazza, J. A. Foster, K. Fucke, P. Metrangolo, G. Resnati and J. W. Steed, Nat. Chem., 2013, 5, 42-47.

6 J. W. Steed, Chem. Commun., 2011, 47, 1379-1383.

7 V. J. Nebot, J. Armengol, J. Smets, S. F. Prieto, B. Escuder and J. F. Miravet, Chem.-Eur. J., 2012, 18, 4063-4072.

8 A. R. Hirst, I. A. Coates, T. R. Boucheteau, J. F. Miravet, B. Escuder, V. Castelletto, I. W. Hamley and D. K. Smith, J. Am. Chem. Soc., 2008, 130, 9113-9121.
9 M. D. Segarra-Maset, V. J. Nebot, J. F. Miravet and B. Escuder, Chem. Soc. Rev., 2013, 42, 7086-7098.

10 H. Maeda, Chem.-Eur. J., 2008, 14, 11274-11282.

11 K. Tiefenbacher, H. Dube, D. Ajami and J. Rebek, Chem. Commun., 2011, 47, 7341-7343.

12 B. Verdejo, F. Rodríguez-Llansola, B. Escuder, J. F. Miravet and P. Ballester, Chem. Commun., 2011, 47, 2017-2019.

13 J. A. Sáez, B. Escuder and J. F. Miravet, Chem. Commun., 2010, 46, 7996-7998.

14 G. O. Lloyd and J. W. Steed, Nat. Chem., 2009, 1, 437-442.

15 A. R. Hirst, B. Escuder, J. F. Miravet and D. K. Smith, Angew. Chem., Int. Ed., 2008, 47, 8002-8018.

16 H. Li, Y. Fujiki, K. Sada and L. A. Estroff, CrystEngComm, 2011, 13, 1060.

17 J. A. Foster, M.-O. M. Piepenbrock, G. O. Lloyd, N. Clarke, J. A. K. Howard and J. W. Steed, Nat. Chem., 2010, 2, 10371043.

18 B. Escuder, F. Rodríguez-Llansola and J. F. Miravet, New J. Chem., 2010, 34, 1044.

19 J. F. Miravet and B. Escuder, Tetrahedron, 2007, 63, 73217325.

20 M.-O. M. Piepenbrock, G. O. Lloyd, N. Clarke and J. W. Steed, Chem. Rev., 2010, 110, 1960-2004.

21 A. Dalla Cort, L. Mandolini, C. Pasquini, K. Rissanen, L. Russo and L. Schiaffino, New J. Chem., 2007, 31, 1633.

22 E. C. Escudero-Adán, J. Benet-Buchholz and A. W. Kleij, Inorg. Chem., 2008, 47, 4256-4263.

23 S. J. Wezenberg, E. C. Escudero-Adán, J. Benet-Buchholz and A. W. Kleij, Org. Lett., 2008, 10, 3311-3314.

24 M. Cano, L. Rodriguez, J. C. Lima, F. Pina, A. Dalla Cort, C. Pasquini and L. Schiaffino, Inorg. Chem., 2009, 48, 62296235.

25 A. Dalla Cort, P. De Bernardin and L. Schiaffino, Chirality, 2009, 21, 104-109.

26 S. J. Wezenberg, E. C. Escudero-Adán, J. Benet-Buchholz and A. W. Kleij, Chem.-Eur. J., 2009, 15, 5695-5700.

27 G. Salassa, M. J. J. Coenen, S. J. Wezenberg, B. L. M. Hendriksen, S. Speller, J. A. A. W. Elemans and A. W. Kleij, J. Am. Chem. Soc., 2012, 134, 7186-7192.

28 I. Pietro Oliveri, S. Failla, G. Malandrino and S. Di Bella, J. Phys. Chem. C, 2013, 117, 15335-15341.

29 J. K. H. Hui, J. K. H. Hui, Z. Yu and M. J. MacLachlan, Angew. Chem., Int. Ed., 2007, 46, 7980-7983.

30 A. Dalla Cort, P. De Bernardin, G. Forte and F. Y. Mihan, Chem. Soc. Rev., 2010, 39, 3863-3874.

31 Z. Džolić, M. Cametti, A. Dalla Cort, L. Mandolini and M. Žinić, Chem. Commun., 2007, 3535-3537.

32 A. Y.-Y. Tam, K. M.-C. Wong, G. Wang and V. W.-W. Yam, Chem. Commun., 2007, 2028-2030.

33 J. K.-H. Hui, Z. Yu, T. Mirfakhrai and M. J. MacLachlan, Chem.-Eur. J., 2009, 15, 13456-13465.

34 I. Pietro Oliveri, G. Malandrino and S. Di Bella, Dalton Trans., 2014, 43, 10208-10214.

35 Scigress, Version FJ 2.4.x, Fujitsu Limited, http://www.fqs.pl/ chemistry_materials_life_science/products/scigress. 